best work done at Panama or with Mussolini's great achievement in the Pontine Marshes; and in area it is vastly greater than either. Moreover, both could learn something to their advantage from India. Nor is this the whole story; for Ceylon, certain areas in British Africa, and Malaya have also fine records in preventing malaria-in Malaya begun even before Panama.

This story would not be complete without mention of how this work was made possible. The late Sir Charles McLeod, first chairman of the Ross Institute, who used to insist that "malaria, malaria, malaria" was the great enemy, and a number of his friends in the City financed the India Branch of the Ross Institute during 19301933, when the responsibility was taken over by the Indian Tea Association.

During this tour I visited the humble laboratory at Hyderabad in which Ronald Ross made his immortal discovery. Often I wished he could have been with me to see how mosquito reduction had spread still farther into rural areas, which as he wrote to me in 1909 he had "never dared to moot".

\title{
THE CORROSION OF FERROUS METALS
}

\author{
By Dr. J. Newton Friend, \\ Central Technical College, Birmingham
}

$\mathrm{I}^{\mathrm{N}}$ 1916 a committee was formed by the Institution of Civil Engineers, under the chairmanship of the late Sir William Matthews, to investigate the "Deterioration of Structures exposed to Sea Action". The Department of Scientific and Industrial Research gave every encouragement and offered substantial financial assistance.

An important section of the work undertaken by the Committee is that dealing with the corrosion of iron and steel. This research has now been completed. Series of bars of fourteen different kinds of ferrous metal, measuring 2 feet in length, 3 inches in width and 0.5 inch in thickness, were exposed at various ports to sea air, to alternate sea air and wetting with sea water or spray, and to continuous immersion in the sea. Three sets were exposed at each port to each of these conditions, one for five years, one for ten and the third for fifteen years. The results obtained with the five and ten year bars have already been fully discussed in the Committee's Fifteenth Report (1935). As yet only the numerical data for the fifteen-year bars have been made public in the Committee's Seventh Interim Report (1938), the full report being temporarily held up on account of the War. It may be said at once that these last results support the earlier ones very satisfactorily, and it is the purpose of this article to mention a few of the more important practical conclusions to be derived from the numerous data now published.

The ports chosen for the exposure of the bars were Auckland (New Zealand), Halifax (Canada), Plymouth (England), and Colombo (Ceylon). These were selected as offering a wide variation in climatic conditions. Thus Colombo has a moist, tropical climate, and the total loss in weight suffered by the bars through corrosion at this port was twice that experienced at Plymouth, three times that at Halifax and nearly four times that at Auckland. Nevertheless, the relative losses among comparable sets of bars were quite analogous and thus enable us to draw many useful conclusions with a high degree of confidence.

The severe nature of the corrosion at Colombo is illustrated in Fig. I. The steel bar Bl4 was perforated near its middle after exposure at halftide level for ten years, whilst, after fifteen years exposure under similar conditions, bar $E 15$, also of mild steel, was completely eaten in two.

At Plymouth three sets of bars were exposed to fresh-water action by immersion in the reservoir at Turnchapel for the above-mentioned periods.

In all cases the bars were maintained in a vertical position by embedding their ends in concrete, which was carefully punned into position so that no air holes or porous sections were left around the metals. The concrete proved an ideal material for the purpose. After fifteen years exposure the metal beneath the concrete was in perfect condition, except in a few cases where the concrete had cracked from one cause or another.

Moist concrete is not a perfect insulator, particularly when impregnated with salt water. Experiments carried out at Plymouth showed that minute electric currents undoubtedly passed through the frames when immersed in the sea. Hence a small amount of electrolytic corrosion was induced in some of the specimens. Most fortunately, measurement showed that this was too small to affect seriously the results, owing to the relatively great distance between the 
experimental bars and the re-inforcing steel rods. Had the specimens been placed appreciably closer either to one another or to the tie-bars, the effect might have been serious. This is a point worth noting in future investigations; it does not appear to have been considered hitherto.

The metals selected for study comprised: (i) three rolled irons, namely, Low Moor, Swedish and ingot irons; (ii) four carbon steels, with carbon ranging from 0.2 to 0.4 per cent; (iii) five alloy steels containing respectively $0 \cdot 6$ and $2 \cdot 2$ per cent copper ; 13.6 per cent chromium ; 3.75 and $36 \cdot 6$ per cent nickel ; (iv) two cast irons, exposed in their 'skins', namely, hot blast metal $Q$ and cold blast metal $R$.

In an exceptionally well-illustrated paper, read before the Institution of Civil Engineers on April 4, 1922, Sir Robert Hadfield gave a detailed account of the preparation, analysis and mechanical testing of these bars. This paper was briefly summarized in NATURE of December 30 of the same year.

As was to be expected, the high nickel steel proved, on the average, the most resistant to all forms of attack. But its high cost and special mechanical properties obviously militate against its general adoption. The chromium steel behaved remarkably well in air and in fresh-water, but in contact with sea-water it suffered such severe localized corrosion as to render it useless.

The cast irons stood up well against aerial corrosion, the cold blast metal proving slightly the more resistant. In contact with water, however, particularly sea-water, graphitization took place, sometimes working its way so deeply into the bar as to leave only a thin core of unattacked

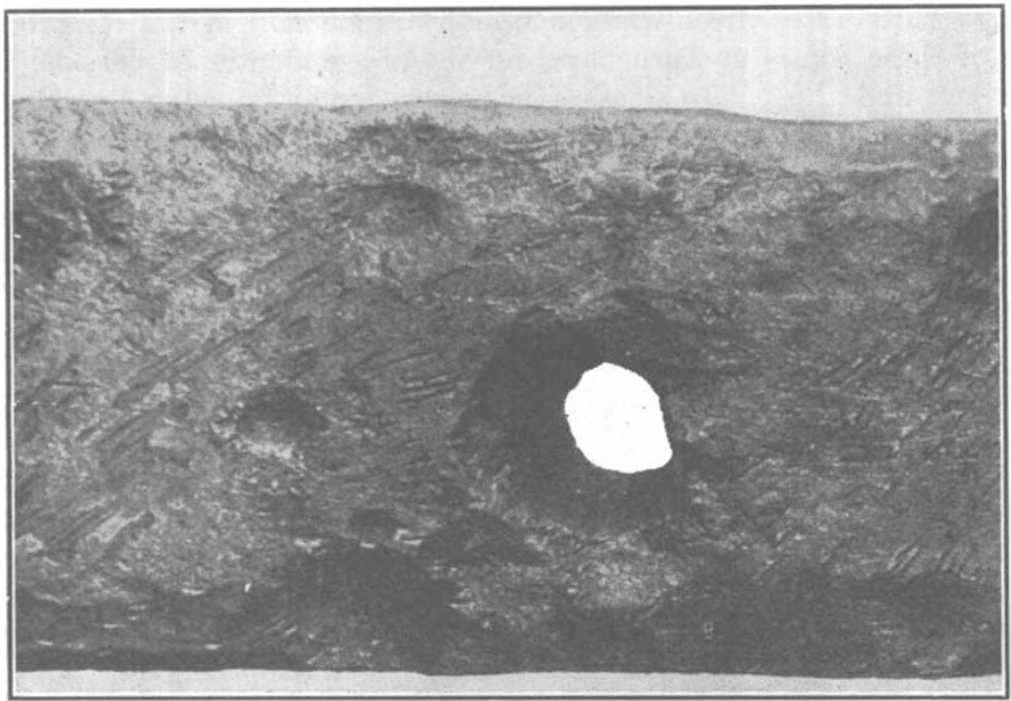

Fig. 1.

MTDD STHEL BAR KXXPOSED FOR TEN YeARS AT HALF-TIDE LEVEL AT CoLOMbo. metal. This is well illustrated in Fig. 2; bars $Q 11$ and $R 11$, exposed to sea air at Colombo for ten years, yielded practically perfect fractures. The fractures of the other bars, exposed at halftide level and to complete immersion in the sea, show how deeply graphitization had penetrated. The corrosion product was hard and so firmly attached to the core that it seemed impossible to remove it by mere mechanical means. Indeed, in some cases it was not until the bars had been intentionally fractured that it was realized how seriously the cast iron had been attacked. The general appearance of the bars was most misleading and, in view of this, cast iron cannot be recommended for purposes other than aerial.

In the aerial tests, Low Moor iron was found to corrode more seriously than mild steel; in fresh-water the two metals behaved pretty much alike; at half-tide level the wrought iron was slightly superior, and when exposed to complete immersion in the sea the wrought iron was decidedly superior. An answer is thus afforded to the vexed question of iron versus steel, in that it is shown to depend upon the type of corrosion to which the metal is destined to be exposed. Mere averaging makes the two metals appear to behave alike.

The foregoing observations clearly prove that if we wish to know which particular metal to choose as most suitable for resisting corrosion, the particular type of corrosion must be specified. No metal is equally resistant to all types of corrosion, and so-called acceleration tests, carried out under conditions different from those to which the metal is destined to be exposed, may easily yield most misleading results. I had already pointed this out in 1911 in my book "The Corrosion of Iron and Steel" (Longmans), p. 276 , and the conclusion arrived at then now receives overwhelming support.

An interesting feature of the research is afforded by the various ways in which the different metals have been attacked under the different conditions of exposure. Thus, for example, the surfaces of most of the bars exposed to sea air alone were covered with innumerable pocks of varying degrees of fineness or coarseness according to circumstances. The wrought irons exposed to seawater were usually covered with furrows or narrow channels running down the full length of the bar, that is, in the direction of rolling. The appearance was 
characteristic and a mere glance enabled one to distinguish between the wrought irons and steels.

Whilst the wrought irons had been exposed in a cleaned condition, that is, ground free from scale, some of the carbon steels had likewise been cleaned, whereas others were exposed with their mill scale still adherent. It is instructive to contrast the behaviour of the steels under these two conditions. The following case is typical. Two mild steel bars, $A 18$ and $E 18$, of the same metal were exposed to complete immersion in the sea at Colombo for fifteen years. Bar $A$ 18, which had been cleaned before exposure, was fairly uniformly attacked and its surface relatively smooth. Bar $E 18$ had been exposed with adherent scale, some of which could still be seen clinging to the metal. But where the scale had broken away, serious localized corrosion had occurred, .analogous to that on $B 14$ (Fig. 1). Some of the

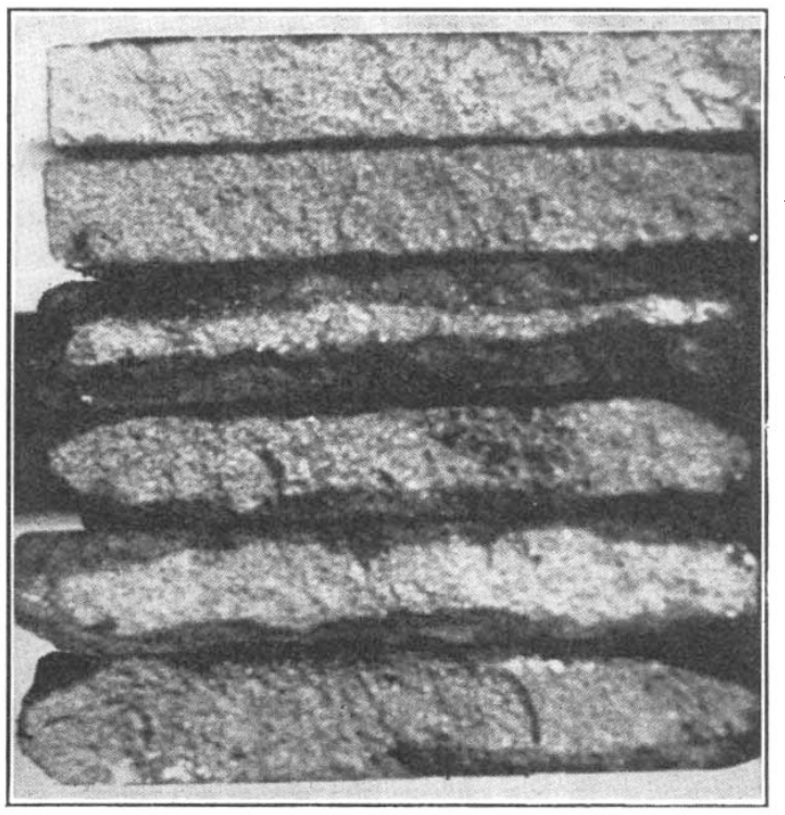

Q11. Aerial

R11. ,

Q14. Half-tide

Fig. 2.

CAST IRON BARS EXPOSED FOR TeN yeARs AT Colombo. $\mathrm{Q}=$ HOT BLAST ; $\mathrm{R}=$ COLD BLAST. pits penetrated more than halfway through the bar. Had two such pits happened to coincide on opposite sides of the bar, as did occur with $B$ 14, the bar would have been perforated and virtually destroyed. The two bars had lost practically the same amounts in weight. Clearly it is most desirable to remove scale from steels destined to be exposed to sea action.

In the case of the bars merely exposed to sea air, it was noted that the cleaned bars usually lost appreciably less in weight than the others-a result that was not expected. The differences in the depths of pitting were less pronounced, it is true, but such advantage as did occur lay again in favour of the cleaned bars.

The general progress of the corrosion of many of the bars exposed at half-tide level and to complete immersion in the sea was often rendered more complex by the presence of shelly fauna. Isolated shelly growths appeared to stimulate corrosion much in the same way as isolated patches of scale. Dead shell-fish seemed particularly deleterious, probably owing to the chemical activity of the organic decomposition products. At Auckland the bars were covered with a thick layer of shelly fauna which appeared to exert a mechanical protective action on the underlying metal. The fauna consisted mainly of barnacles and oysters; the former covered the bars whilst the oysters rested on top of the barnacles. In one case only was an oyster found to be in direct contact with the metal, and the position it had occupied was faintly discernible, after cleaning, as a slight depression on the steel.

Turning now to the alloy steels, it may be mentioned that the presence of $0 \cdot 6$ per cent copper greatly enhanced the resistance of the steel to sea air and to fresh-water. In contact with sea-water, the effect either way was small. Increasing the percentage of copper to two did not, in general, effect much improvement ; indeed, in some cases it seemed disadvantageous. Any added cost thereby entailed would certainly not be justified.

The addition of 3.75 per cent of nickel effected a very great reduction in the corrosion of the bars exposed either to sea air alone or to fresh-water. At half-tide level and when completely immersed in sea-water, the nickel steel still proved superior to the copper steel, but less markedly so.

One point in connexion with the alloy steels would appear to be important, namely, that in general they show a greater tendency to localized corrosion or pitting than do ordinary carbon steels in contact with sea-water. Mention has already been made of the severe localized corrosion suffered by the chromium steel.

The full report of the Committee, when published, will contain valuable material. In a brief summary such as this, it is obviously possible to deal with only a few of the interesting results obtained. The present chairman of the Committee is Mr. W. T. Halcrow, and it is to be sincerely hoped that this valuable work may be continued as soon as circumstances permit. 